๑ Open Access Full Text Article

CORRIGENDUM

\title{
Codelivery of Doxorubicin and MDRI-siRNA by Mesoporous Silica Nanoparticles-Polymerpolyethylenimine to Improve Oral Squamous Carcinoma Treatment [Corrigendum]
}

\author{
Wang $\mathrm{D}, \mathrm{Xu} \mathrm{X}$, Zhang $\mathrm{K}$, et al. Int $J$ Nanomedicine. \\ 2018;13:187-198. \\ The authors have advised due to an error at the time of \\ figure assembly, Figure 5 on page 195 is incorrect. The \\ correct Figure 5 is as follows.
}

The authors apologize for this error and advise it does not affect the results of the paper. 

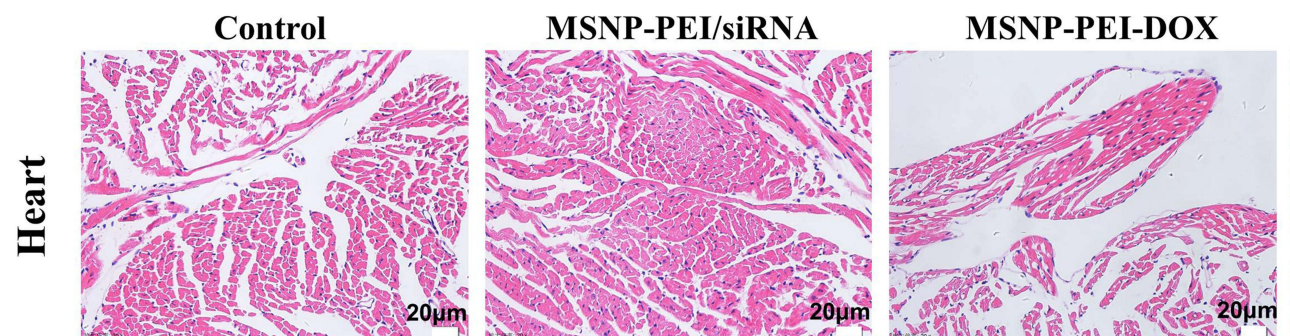

MSNP-PEI-DOX/SIRNA
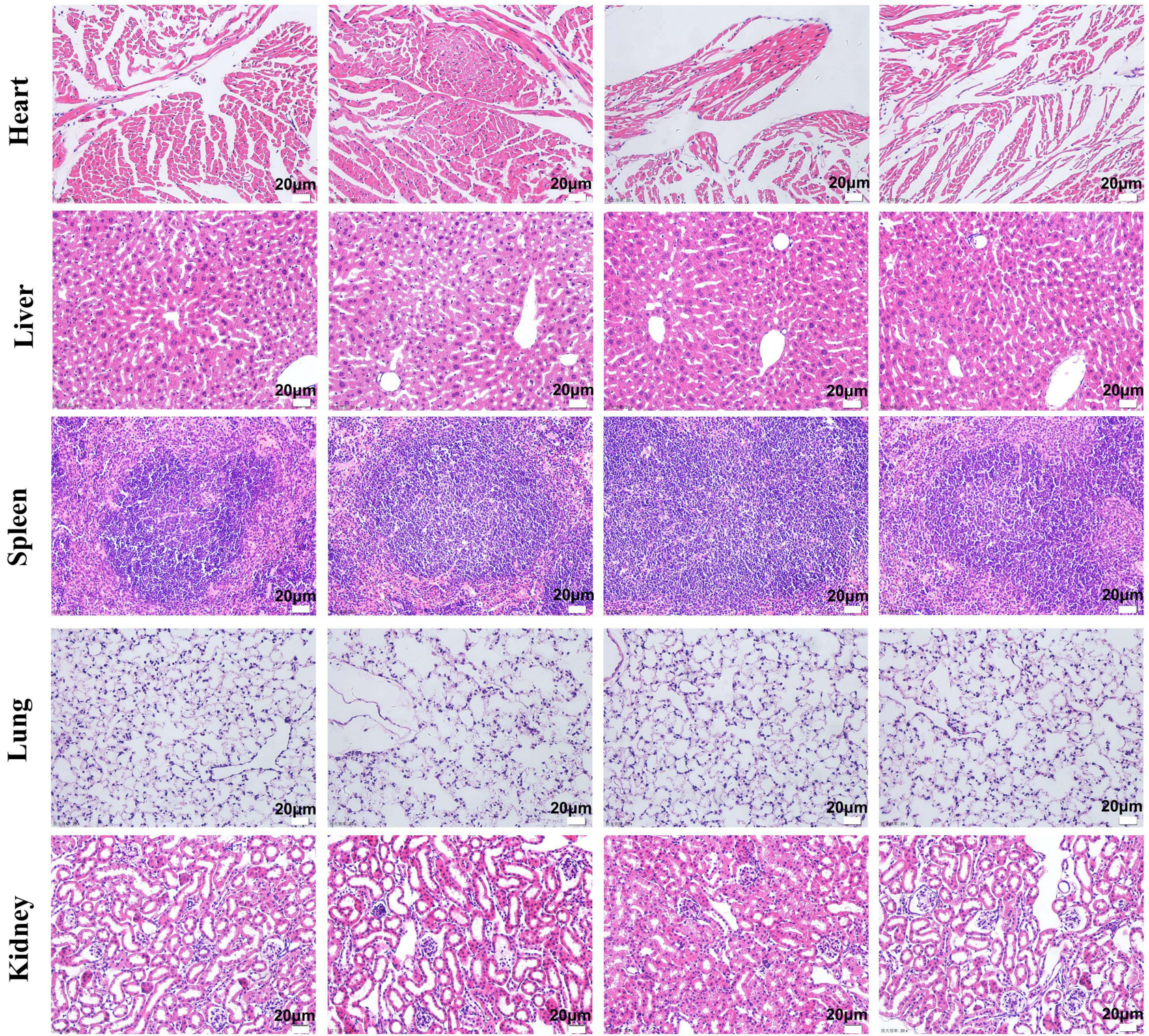

Figure 5 H\&E staining of heart, liver, spleen, lung, and kidney; $\times 200$.

Abbreviations: DOX, doxorubicin; H\&E, hematoxylin and eosin; MDR, multidrug resistance; MSNP, mesoporous silica nanoparticles; PEI, polymerpolyethylenimine.

\section{Publish your work in this journal}

The International Journal of Nanomedicine is an international, peerreviewed journal focusing on the application of nanotechnology in diagnostics, therapeutics, and drug delivery systems throughout the biomedical field. This journal is indexed on PubMed Central, MedLine, CAS, SciSearch ${ }^{\circledR}$, Current Contents ${ }^{\mathbb{B}} /$ Clinical Medicine, $^{2}$
Journal Citation Reports/Science Edition, EMBase, Scopus and the Elsevier Bibliographic databases. The manuscript management system is completely online and includes a very quick and fair peer-review system, which is all easy to use. Visit http://www.dovepress.com/ testimonials.php to read real quotes from published authors. 